Research Article

\title{
Effects of Reinforcing Fiber and Microsilica on the Mechanical and Chloride Ion Penetration Properties of Latex-Modified Fiber-Reinforced Rapid-Set Cement Concrete for Pavement Repair
}

\author{
Woong Kim, ${ }^{1}$ Jong-Chan Jeon, ${ }^{2}$ Byung-Hwan An, ${ }^{2}$ Joo-Ha Lee, ${ }^{3}$ Hae-Do Kim, \\ and Chan-Gi Park $\mathbb{D D}^{2}$ \\ ${ }^{1}$ Department of Bio-Industry Mechanical Engineering, Kongju National University, Yesan 32439, Republic of Korea \\ ${ }^{2}$ Department of Rural Construction Engineering, Kongju National University, Yesan 32439, Republic of Korea \\ ${ }^{3}$ Department of Civil Engineering, University of Suwon, Hwaseong 18323, Republic of Korea \\ ${ }^{4}$ Rural Research Institute, Korea Rural Community Corporation, Ansan 15634, Republic of Korea
}

Correspondence should be addressed to Chan-Gi Park; cgpark@kongju.ac.kr

Received 22 August 2017; Accepted 29 October 2017; Published 21 January 2018

Academic Editor: Young Hoon Kim

Copyright (c) 2018 Woong Kim et al. This is an open access article distributed under the Creative Commons Attribution License, which permits unrestricted use, distribution, and reproduction in any medium, provided the original work is properly cited.

\begin{abstract}
This study evaluated the influence of reinforcement fiber type and microsilica content on the performance of latex-modified fiberreinforced roller-compacted rapid-hardening cement concrete (LMFRCRSC) for a concrete pavement emergency repair. Experimental variables were the microsilica substitution ratio $(1,2,3$, and $4 \%$ ), and the reinforcement fiber (jute versus macrosynthetic fiber). In the tests, compressive, flexural, and splitting tensile strength; chloride ion penetration resistance; and abrasion resistance were assessed. From the compressive and flexural strength tests with microsilica substitution, the 4-hour curing strength decreased as the microsilica substitution ratio increased. From the chloride ion penetration test, as the microsilica substitution ratio increased, chloride ion penetration decreased. The abrasion resistances increased with the substitution ratio of microsilica increase. Based on these test results, microsilica at a substitution ratio of $3 \%$ or less and macrosynthetic fiber as the reinforcement improved the performance of LMFRCRSC for a concrete pavement emergency repair and satisfied all of the target strength requirements.
\end{abstract}

\section{Introduction}

The repair of deteriorated concrete pavements, using rollercompacted latex-modified rapid-hardening cement concrete, has been studied recently [1]. A roller-compacted concrete (RCC) is a concrete with low fluidity [2-6]. RCC does not require a consistency for compacting, and it must be compacted with an external vibrator, such as a vibration roller or a vibration pressure tamper [2]. Roller-compacted concrete pavement (RCCP) offers a fast, successive construction and use of a wide range of construction equipment; thus, it has higher economic feasibility than other concrete pavements [2-6]. Compared with a general concrete pavement, RCCP has a lower water-to-cement (W/C) ratio [2]. A lower $\mathrm{W} / \mathrm{C}$ ratio has the effect of increasing the strength of concrete, and it may reduce the risk of contraction cracks due to moisture evaporation [2-6]. Thus, RCCP also has the advantage of increased durability of pavement over the long term [2-6]. When RCC and latex are used with rapidhardening cement for a concrete pavement, it is possible to achieve both easy construction and durability [1]. Currently, roller-compacted rapid-hardening cement concrete pavement uses up to $15 \%$ latex [1]. The use of latex up to $15 \%$ may delay the concrete's initial strength development. As such, it may be difficult to secure sufficient initial target strength $[7,8]$. Economically, the overall concrete pavement 
repair is more costly due to the high latex amounts. The latex-modified rapid-hardening cement offers superior workability, crack resistance, and durability compared to the general rapid-hardening cement concrete [8-15], but it has the problems of initial strength development delay and lower economic feasibility. Also, the increase in initial fluidity makes roller compaction difficult because latex-modified fiber-reinforced roller-compacted rapid-hardening cement concrete (LMFRCRSC) uses a mix that has low slump, due to the characteristics of RCC.

In the previous study [16], the performance of LMFRCRSC according to the type of fiber reinforcement was evaluated. The possibility of the roller compaction method was evaluated by measuring the slump value according to the type of fiber reinforcement. Mechanical properties such as compressive strength and flexural strength were evaluated, and durability such as permeability and abrasion resistance were evaluated. However, the using amount of rapid-hardening cement is not reduced, so there is a limit to solving the problems caused by the increase in hydration heat in the early age. Therefore, it is necessary to reduce the using amount of rapid-hardening cement. The study was conducted to apply microsilica as a substitute material for rapid-hardening cement in order to reduce the using amount of rapid-hardening cement. The addition of microsilica brings about the pozzolanic reaction and a fine pore-filling effect, providing increased strength and improved water tightness [16, 17]. Also, this study added macrosynthetic fibers and natural jute fibers which showed good results in the previous study. A fiber reinforcement minimizes crack formation and propagation in concrete through the fiber's fracture, pullout, debonding, and bridging effects [13-15]. As a result, the addition of the reinforcement fiber improves the tensile strength of concrete [13-15]. The influence of reinforcement fiber type and microsilica content on the performance of LMFRCRSC was evaluated for a concrete pavement emergency repair.

\section{Materials}

2.1. Materials. A rapid-hardening cement used was the product manufactured by Jungang Polytech, Korea. Physical and chemical characteristics of the rapid-hardening cement are shown in Table 1. A microsilica, a product from Micro Chemical, Korea, was used for this study, and its chemical compositions are shown in Table 2. Also, the microsilica consists of spherical particles with an average particle size of $0.15 \mu \mathrm{m}$ and a specific surface area of $20 \mathrm{~m}^{3} / g$. The coarse aggregate was the crushed aggregate with a maximum diameter of $13 \mathrm{~mm}$. The fine aggregate was river sand, with a specific gravity of 2.58 . The physical characteristics of the aggregates are listed in Table 3 . A styrene butadiene latex (SB latex) from Jungang Polytech, Korea, was used for this study, and its characteristics are given in Table 4. The macrosynthetic fiber and natural jute fiber were purchased from Nycontech, Korea, and the fiber characteristics are shown in Table 5. The shapes of the fibers are shown in Figure 1 [16].
TABLE 1: Chemical compositions of rapid-hardening cement.

\begin{tabular}{lcccccc}
\hline $\begin{array}{l}\mathrm{SiO}_{2} \\
(\%)\end{array}$ & $\begin{array}{c}\mathrm{Al}_{2} \mathrm{O}_{3} \\
(\%)\end{array}$ & $\begin{array}{c}\mathrm{Fe}_{2} \mathrm{O}_{3} \\
(\%)\end{array}$ & $\begin{array}{c}\mathrm{CaO} \\
(\%)\end{array}$ & $\begin{array}{c}\mathrm{MgO} \\
(\%)\end{array}$ & $\begin{array}{c}\mathrm{K}_{2} \mathrm{O} \\
(\%)\end{array}$ & $\begin{array}{c}\mathrm{SO}_{3} \\
(\%)\end{array}$ \\
\hline $13 \pm 3$ & $17.5 \pm 3$ & $3>$ & $50 \pm 3$ & $2.5>$ & 0.21 & $14 \pm 3$ \\
\hline
\end{tabular}

TABLE 2: Chemical compositions of microsilica.

\begin{tabular}{lcccc}
\hline $\mathrm{SiO}_{2}(\%)$ & $\mathrm{Al}_{2} \mathrm{O}_{3}(\%)$ & $\mathrm{Fe}_{2} \mathrm{O}_{3}(\%)$ & $\mathrm{CaO}(\%)$ & Others (\%) \\
\hline $90-98$ & $0.4-0.9$ & $1-2$ & $0.2-0.7$ & $2-3$ \\
\hline
\end{tabular}

TABle 3: Physical properties of coarse aggregates.

\begin{tabular}{lccc}
\hline Properties & $\begin{array}{c}\text { Density } \\
\left(\mathrm{g} / \mathrm{mm}^{3}\right)\end{array}$ & Absorption (\%) & Fineness modulus \\
\hline Value & 2.61 & 0.35 & 6.92 \\
\hline
\end{tabular}

2.2. Mix Proportions. In case of concrete pavement repaired using rapid-hardening cement, the traffic open time is specified as a 4-hour minimum curing time by the American Association of State Highway and Transportation Officials (AASHTO) [18], the road traffic administrations of each state in the United States, and the Korea Expressway Corporation [19]. The traffic open standard is a compressive strength of at least $21 \mathrm{MPa}$ and a flexural strength of at least 3.5 MPa. After curing for 28 days, the compressive strength is required to be at least $35 \mathrm{MPa}$, with a flexural strength of $4.5 \mathrm{MPa}$ and a splitting tensile strength of $4.2 \mathrm{MPa}$. The abovementioned strength criteria were used as target mix strengths for this study. In addition, permeability has the biggest influence on concrete pavement life cycle degradation. In terms of durability, a chloride ion penetration test result of $\leq 2000$ Coulombs (C) after 28 days of curing was set as a target for permeability, based on the Korea Expressway Corporation's ASTM C1202 test method. Also, in this study, to ensure initial permeability, the target chloride ion penetration at 4 hours of curing was set at $4000 \mathrm{C}$ or less.

The W/C ratio was set at 0.28 , and latex at $5 \%$ (solidbased) of the binder (cement + microsilica) weight was used. In the preliminary study [16], it was decided to apply about $5 \%$, considering the range of latex that can be roller compaction methods on the type of fiber reinforcement. The reinforcement fibers, macrosynthetic fiber and jute fiber, were added at a volume ratio of $0.10 \%$. The addition of reinforcement fibers facilitates slump reduction for roller compaction and is effective for controlling crack formation/growth and reducing water penetration. Microsilica was substituted for cement at weights of $0,1,2,3$, and $4 \%$ to evaluate the influence of the addition of microsilica. The study mix ratios are shown in Table 6 .

2.3. Manufacturing of Test Specimens. For test specimens of LMFRCRSC, this study manufactured specimens using a pressure tamper, which mimicked the roller compaction process. In the first step of specimen fabrication, one-third of the mixed latex-modified fiber-reinforced rapid-hardening 
Table 4: Properties of styrene butadiene latex.

\begin{tabular}{lccccccc}
\hline $\begin{array}{l}\text { Solid } \\
\text { content } \\
(\%)\end{array}$ & $\begin{array}{c}\text { Styrene } \\
\text { content } \\
(\%)\end{array}$ & $\begin{array}{c}\text { Butadiene } \\
\text { content }(\%)\end{array}$ & $\mathrm{pH}$ & $\begin{array}{c}\text { Specific } \\
\text { gravity }\end{array}$ & $\begin{array}{c}\text { Surface } \\
\text { tension } \\
(\text { dyne/cm })\end{array}$ & $\begin{array}{c}\text { Particle } \\
\text { size }(\mathrm{A})\end{array}$ & $\begin{array}{c}\text { Viscosity } \\
(\mathrm{cps})\end{array}$ \\
\hline 49 & $34 \pm 1.5$ & $66 \pm 1.5$ & 11.0 & 1.02 & 30.57 & 1700 \\
\hline
\end{tabular}

TABle 5: Properties of fibers.

\begin{tabular}{lcc}
\hline Properties & $\begin{array}{c}\text { Macrosynthetic } \\
\text { fiber }\end{array}$ & $\begin{array}{c}\text { Natural jute } \\
\text { fiber }\end{array}$ \\
\hline Elastic modulus $(\mathrm{GPa})$ & 10 & 61 \\
Density $\left(\mathrm{g} / \mathrm{mm}^{3}\right)$ & 0.91 & 1.26 \\
Fiber length $(\mathrm{mm})$ & 30 & 3 \\
Fiber diameter $(\mathrm{mm})$ & 1 & 0.015 \\
Tensile strength $(\mathrm{MPa})$ & 550 & 510 \\
\hline
\end{tabular}

cement concrete was poured for specimens, and the vibration and pressure tamper was used to apply vibration pressure for $30 \mathrm{~s}$. Similarly, the second third was poured, and $30 \mathrm{~s}$ of pressure vibration compaction was carried out. The final third was poured, pressure vibration compaction was carried out, and the surface was finished. The specimens were then evaluated in terms of performance. Figure 2 shows the vibration and pressure tamper used and the specimens manufactured using the vibration and pressure tamper [16].

\section{Test Methods}

3.1. Compressive Strength Tests. Compressive strength tests were performed in accordance with the ASTM C 39 standard [20]. Tests were performed after 4 hours and 28 days of curing. Each variable was investigated using six specimens.

3.2. Splitting Tensile Tests. Splitting tensile tests were conducted in accordance with the ASTM C 496 standard [21]. Tests were performed after 4 hours and 28 days of curing. Specimens $(\varnothing 100 \times 200 \mathrm{~mm})$ were cured in water at $23 \pm 2^{\circ} \mathrm{C}$. Each variable was investigated using six specimens.

3.3. Flexural Tests. Flexural tests were conducted in accordance with the ASTM C 496 standard [22]. Tests were performed after 4 hours and 28 days of curing. Specimens $(100 \mathrm{~mm} \times 100 \mathrm{~mm} \times 400 \mathrm{~mm})$ were cured in water at $23 \pm$ $2^{\circ} \mathrm{C}$. Each variable was investigated using six specimens.

3.4. Chloride Ion Penetration Tests. Chloride ion penetration tests were conducted in accordance with the ASTM C 1202-94 standard [23]. Specimens, $150 \mathrm{~mm} \times 50 \mathrm{~mm}$ in size, were tested after 28 days of curing. Each variable was investigated using six specimens. The test apparatus for the chloride ion penetration test is shown in Figure 3 [16].

3.5. Abrasion Tests. Abrasion tests were conducted in accordance with the ASTM C 944 standard [24]. Specimens,
$150 \mathrm{~mm} \times 60 \mathrm{~mm}$ in size, were tested after 7 days of curing. Each variable was investigated using six specimens. The test apparatus for the abrasion test is shown in Figure 4 [16].

\section{Results and Discussion}

4.1. Compressive Strength. Figure 5 shows the compressive strength test results of LMFRCRSC for a concrete pavement emergency repair according to the reinforcement fiber type and microsilica substitution ratio. Generally, when pressure vibration compaction is used, the resulting concrete is more dense and may show increased compressive strength. On mixing with jute fibers, the 4-hour curing target compressive strength of at least $21 \mathrm{MPa}$ was satisfied up to a microsilica substitution ratio of $2 \%$. Also, on mixing with macrosynthetic fibers, the target compressive strength was satisfied up to a microsilica substitution ratio of $3 \%$. As the microsilica substitution ratio increased, the compressive strength decreased. Rapid-hardening cement promotes hydration, with an active reaction of $3 \mathrm{CaO} \cdot \mathrm{SiO}_{2}$, generating acicular crystals of ettringite by the reaction of calcium silicate hydrate (CSH) gel and calcium sulfoaluminate (CSA); this increases the initial strength. With microsilica substituting for rapid-hardening cement, the $3 \mathrm{CaO} \cdot \mathrm{SiO}_{2}$ ingredient is present in a smaller proportion, causing a delay in compressive strength development in the early stages. For the 4-hour compressive strength, in cases using jute fibers, as the microsilica substitution ratio increased from 0 to $1,2,3$, and $4 \%$, the compressive strengths were $22.1,21.8,21.3,16.2$, and 15.4 MPa, respectively. Using macrosynthetic fibers, as the microsilica substitution ratio increased from 0 to $1,2,3$, and $4 \%$, the compressive strengths were $27.5,24.5,23.0,20.8$, and 15.8 MPa, respectively. The cases using macrosynthetic fibers showed higher compressive strengths than those using jute fibers. Fiber-reinforcing materials can be classified into structural fibers to improve structural performance, such as strength, and nonstructural fibers to be used for crack control and durability improvement $[15,16]$. In this study, macrosynthetic fibers, which can replace steel fibers as structural fibers, were applied, while jute fibers were incorporated as nonstructural fibers $[15,16]$. Also, jute fiber is a natural fiber; thus, it is more difficult to maintain the quality. The jute fiber's main ingredient contains cellulose and a small amount of lignin. Lignin has the effect of delaying the concrete's compressive strength development.

The 28-day curing compressive strength results showed that the target of $35 \mathrm{MPa}$ was satisfied by the results with all mixes. As the microsilica substitution ratio increased, compressive strength increased. The microsilica additive improved the performance of the concrete via the pozzolanic reaction and the fine pore-filling effect. These tendencies 


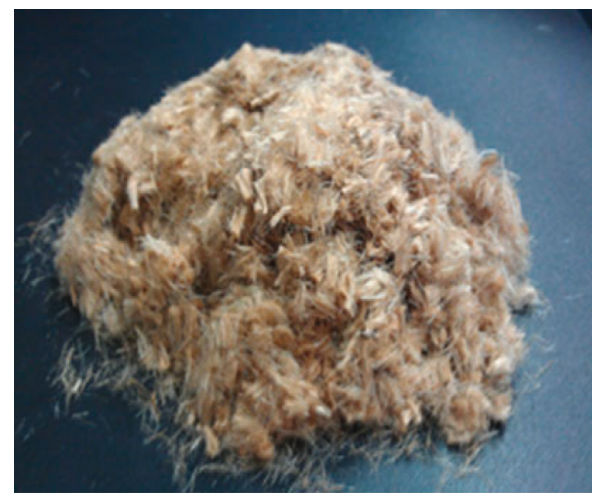

(a)

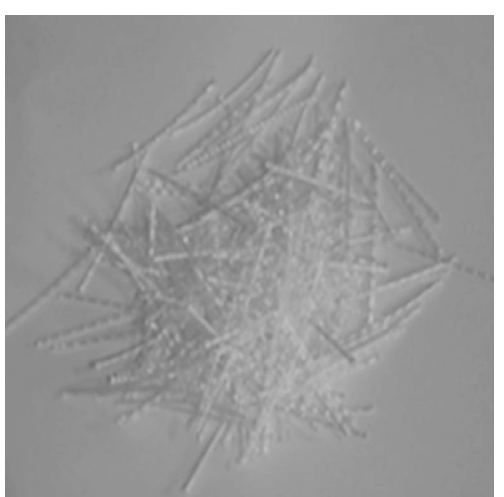

(b)

Figure 1: Geometry of fibers [16]. (a) Jute fiber. (b) Macrosynthetic fiber.

TABLE 6: Mix proportions of LMFRCRSC for a pavement repair.

\begin{tabular}{|c|c|c|c|c|c|c|c|c|c|c|c|}
\hline \multirow[b]{2}{*}{ Mix no. } & \multirow{2}{*}{$\begin{array}{c}W^{*} / B^{* *} \\
(\%)\end{array}$} & \multirow{2}{*}{$\begin{array}{l}S / A \\
(\%)\end{array}$} & \multicolumn{9}{|c|}{ Unit weight $\left(\mathrm{kg} / \mathrm{m}^{3}\right)$} \\
\hline & & & $W$ & $C$ & Macrosilica & $S$ & $G$ & $\begin{array}{l}\text { Latex } \\
\text { (solid) }\end{array}$ & $\begin{array}{l}\text { Water in } \\
\text { latex }\end{array}$ & $\begin{array}{l}\text { Macrosynthetic } \\
\text { fiber }\end{array}$ & $\begin{array}{l}\text { Jute } \\
\text { fiber }\end{array}$ \\
\hline Macrosynthetic-0 & \multirow{10}{*}{28} & \multirow{10}{*}{55} & \multirow{10}{*}{91} & 400 & 0 & \multirow{10}{*}{1015} & \multirow{10}{*}{831} & \multirow{10}{*}{20} & \multirow{10}{*}{21} & \multirow{10}{*}{0.91} & \multirow{7}{*}{-} \\
\hline Macrosynthetic-1 & & & & 396 & 4 & & & & & & \\
\hline Macrosynthetic-2 & & & & 392 & 8 & & & & & & \\
\hline Macrosynthetic-3 & & & & 388 & 12 & & & & & & \\
\hline Macrosynthetic-4 & & & & 384 & 16 & & & & & & \\
\hline Jute-0 & & & & 400 & 0 & & & & & & \\
\hline Jute-1 & & & & 396 & 4 & & & & & & \\
\hline Jute-2 & & & & 392 & 8 & & & & & & 1.26 \\
\hline Jute-3 & & & & 388 & 12 & & & & & & \\
\hline Jute-4 & & & & 384 & 16 & & & & & & \\
\hline
\end{tabular}

${ }^{*} W+$ water in latex. ${ }^{* *}$ Cement + microsilica.

were also seen in the mixes with added jute and macrosynthetic fibers. The compressive strength was higher with macrosynthetic fibers than with jute fibers.

4.2. Flexural Strength. The flexural strength test results of LMFRCRSC for a concrete pavement emergency repair by reinforcement fiber types and the microsilica substitution ratio are shown in Figure 6. On mixing with jute fibers, the results showed that the 4-hour curing target flexural strength of 3.5 MPa was satisfied up to a microsilica substitution ratio of $2 \%$. When the macrosynthetic fiber was included, the target flexural strength was satisfied up to a microsilica substitution ratio of $3 \%$. As the microsilica substitution ratio increased, the flexural strength decreased. Rapid-hardening cement promotes hydration, with an active reaction of $3 \mathrm{CaO} \cdot \mathrm{SiO}_{2}$, generating acicular crystals of ettringite by the reaction of CSH gel and CSA. With microsilica substituting for rapid-hardening cement, the $3 \mathrm{CaO} \cdot \mathrm{SiO}$ ingredient is present in a relatively lower proportion, causing a delay in strength development in the early stages. Thus, the strength is lower. The cases using macrosynthetic fibers showed higher flexural strengths than those using jute fibers. The 28-day curing flexural strength results showed that the target of $4.5 \mathrm{MPa}$ was satisfied by all mixes. Generally, latex and reinforcement fibers have more influence on flexural strength than on compressive strength. Thus, in this study, latex and reinforcement fibers were used. The mix with no microsilica added had the highest flexural strength. Moreover, pressure vibration compaction was used to densify the concrete structure; it was effective in increasing the concrete's strength. Thus, after curing for 28 days, the flexural strength satisfied the target strength of $\geq 4.5 \mathrm{MPa}$. As the microsilica substitution ratio increased, the flexural strength increased slightly. Microsilica improves the performance of the concrete, due to the pozzolanic reaction and the fine pore-filling effect. Thus, in the case of longterm strength, the flexural strength increased with the substitution ratio. This tendency was also seen in the mixes with added jute and macrosynthetic fibers. The flexural strength was slightly higher with macrosynthetic fibers than with jute fibers.

4.3. Splitting Tensile Strength. The splitting tensile strength results of LMFRCRSC for a concrete pavement emergency 



(a)
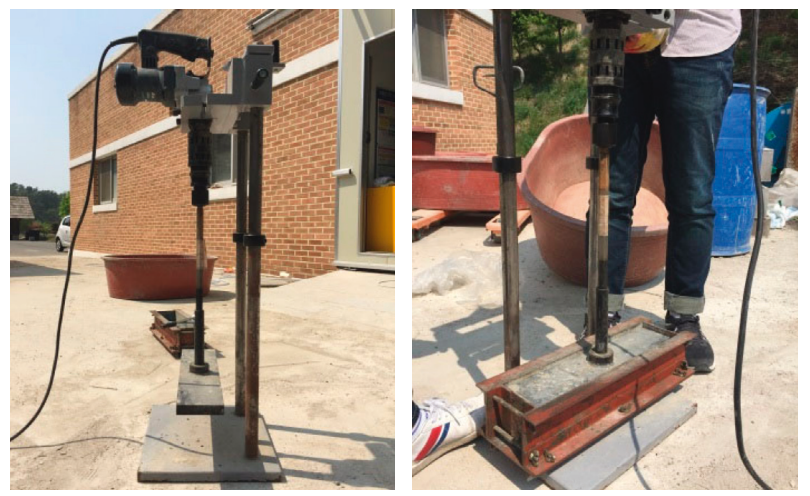

(b)

Figure 2: Manufacturing of test specimens [16]. (a) Manufacturing of compressive strength specimens. (b) Manufacturing of flexural strength specimens.

repair by the reinforcement fiber type and the microsilica substitution ratio are shown in Figure 7. The results showed that the mixes satisfied the 28-day splitting tensile strength target of $\geq 4.2 \mathrm{MPa}$. In this study, pressure vibration compaction was used to densify the concrete structure and was effective in increasing the concrete's strength. Thus, after curing for 28 days, the splitting tensile strength satisfied the target of $\geq 4.2 \mathrm{MPa}$. The addition of latex and reinforcement fibers has more influence on tensile strength than on compressive strength. Thus, when latex and reinforcement fibers were added, splitting tensile strength also increased. All mixes satisfied the target of $\geq 4.2 \mathrm{MPa}$ splitting tensile strength. Splitting tensile strength increased slightly as the microsilica substitution ratio increased; this was attributed to the pozzolanic reaction and filling of fine pores by the microsilica additive. The pozzolanic reaction has the effect of increasing the long-term strength. Moreover, while latex delays initial strength development, it increases the longterm strength. The splitting tensile strength was higher with macrosynthetic fibers than with jute fibers. This is because the macrosynthetic fiber is a structural fiber, which is used to replace the steel fiber and improves the structural performance of the concrete $[16,25,26]$. However, jute fibers are crack-control fibers, which are used to improve durability rather than structural performance $[16,27]$.



Figure 3: Chloride ion penetration test setup [16].



Figure 4: Abrasion test setup [16].

4.4. Chloride Ion Penetration. The chloride ion penetration resistance results of LMFRCRSC for a concrete pavement emergency repair by the reinforcement fiber type and the microsilica substitution ratio are shown in Figure 8. In the chloride ion penetration tests conducted after 28 days of curing, all mixes showed values lower than the target $2000 \mathrm{C}$. In this study, pressure vibration compaction was used to densify the concrete structure. Thus, with 28 days of curing, all mixes satisfied the target chloride ion penetration amount of $\leq 2000 \mathrm{C}$. Also, the target value of $4000 \mathrm{C}$ or less at $4 \mathrm{~h}$ of curing was satisfied for all mix ratios. In the case of rapidhardening cement concretes, cracks occur inside the cement due to high hydration heat in the early stages [1-3]. The addition of reinforcement fibers appeared to offset hydration heat-induced crack formation $[5,12]$. Because the reinforcing fibers inhibit the internal cracks due to the generation of hydration heat before sufficient strength is developed, the chlorine ion penetration amount decreases. For the 4-hour curing stage, all mixes showed moderate water penetration properties. The reinforcing fibers inhibit internal crack formation due to the generation of hydration heat before sufficient strength develops. Therefore, it can be concluded that the addition of reinforcing fibers is effective in reducing chloride ion penetration at the initial curing period in the repair concrete. After curing for 28 days, all 


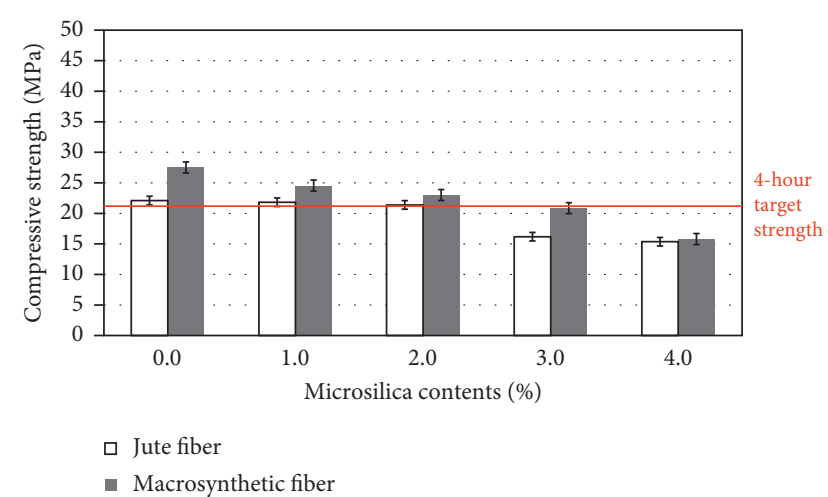

(a)

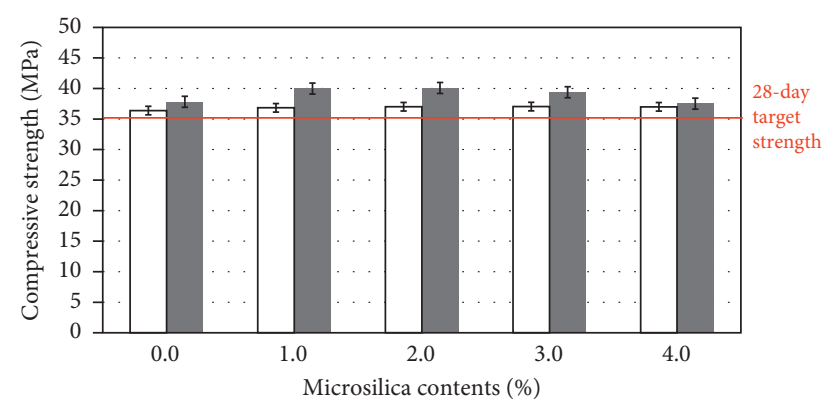

Jute fiber

- Macrosynthetic fiber

(b)

FIGURE 5: Compressive strength of LMFRCRSC. (a) 4-hour curing. (b) 28-day curing.

mixes showed low-level penetration at up to $2 \%$ microsilica content. When the microsilica content exceeded 3\%, lowlevel permeability was observed. Also, the results showed decreased chloride ion penetration in cases using macrosynthetic fibers versus those using jute fibers. The main ingredient of the jute fiber is cellulose, plus a small amount of lignin. Lignin has the effect of delaying the concrete's strength development $[16,27]$. Therefore, the hardening was insufficient, and the chloride ion permeability was enhanced.

4.5. Abrasion Resistance. The abrasion test results of LMFRCRSC for a concrete pavement emergency repair by the reinforcement fiber type and the microsilica substitution ratio are shown in Figure 9. As the microsilica substitution ratio increased, the results showed decreased abrasion on the concrete surface. This is because when microsilica is added to the concrete, the pozzolanic reaction and the fine porefilling effect create a more dense concrete structure with improved abrasion resistance. By the fiber reinforcement type, the results showed increased abrasion resistance in the cases using macrosynthetic fibers versus those using jute fibers. However, the difference in the results was not significant.

\section{Conclusions}

This study evaluated the influence of reinforcement fiber types and microsilica on the performance of LMFRCRSC for



(a)



(b)

FIgURE 6: Flexural strength of LMFRCRSC. (a) 4-hour curing. (b) 28-day curing.

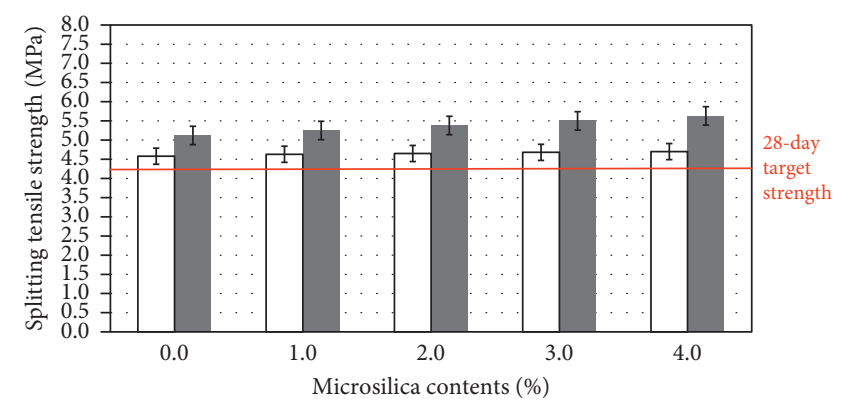

$\square$ Jute fiber

- Macrosynthetic fiber

Figure 7: Splitting tensile strength of LMFRCRSC.

a concrete pavement emergency repair. A summary of the test results is given below:

(i) In the compressive strength and flexural strength tests with curing for $4 \mathrm{~h}$, the strength decreased as the microsilica substitution ratio increased. For the jute fiber-reinforced concrete mix with 4-hour curing, a target compressive strength of $\geq 21 \mathrm{MPa}$ and target flexural strength of $\geq 3.5 \mathrm{MPa}$ were achieved up to a microsilica substitution ratio of $2 \%$. When the macrosynthetic fiber was mixed, the 4-hour curing target strength was satisfied up to a microsilica substitution ratio of $3 \%$. 




Jute fiber

- Macrosynthetic fiber

(a)

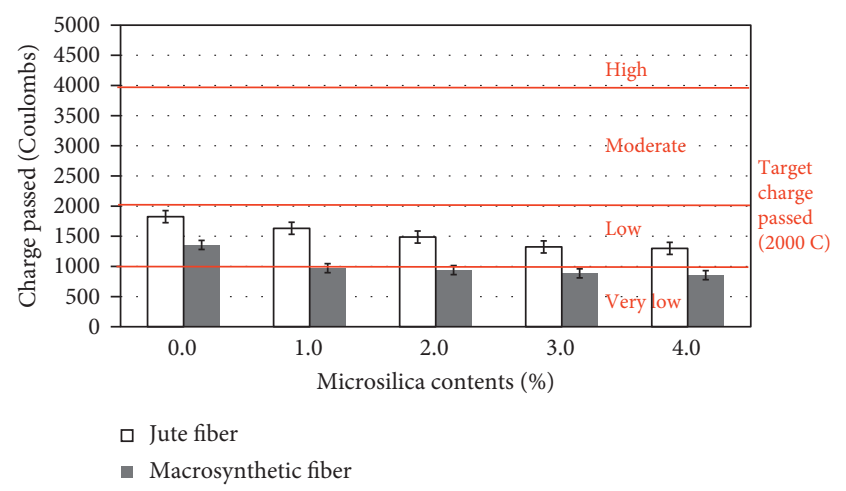

(b)

FIGURE 8: Chloride ion penetration of LMFRCRSC. (a) 4-hour curing. (b) 28-day curing.

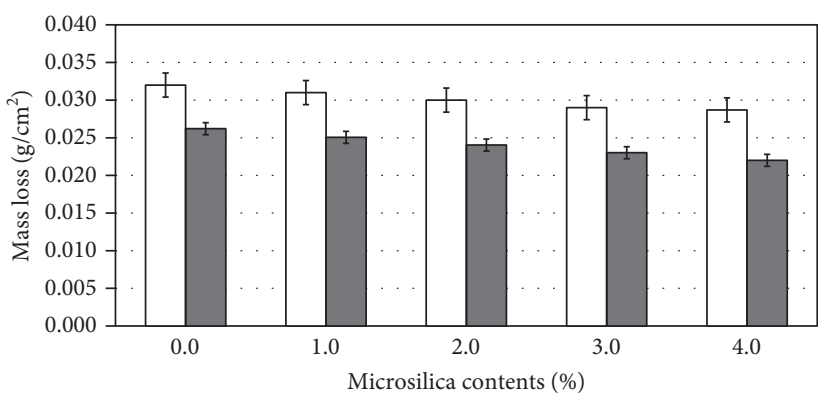

口 Jute fiber

- Macrosynthetic fiber

FIGURE 9: Abrasion resistance of LMFRCRSC.

(ii) With curing for 28 days, the compressive strength, flexural strength, and splitting tensile strength increased as the microsilica substitution ratio increased. Also, with curing for 28 days, the target compressive strength $(\geq 35 \mathrm{MPa})$, flexural strength $(\geq 4.5 \mathrm{MPa})$, and splitting tensile strength $(\geq 4.2 \mathrm{MPa})$ were all satisfied.

(iii) In terms of compressive, flexural, and splitting tensile strength test results, cases with macrosynthetic fibers showed higher values than cases with jute fibers.

(iv) From the chloride ion penetration tests, as the microsilica substitution ratio increased, the chloride ion penetration decreased. All mixes satisfied the target chloride ion penetration of $\leq 2000 \mathrm{C}$ after curing for 28 days. Regarding the reinforcement fiber, chloride ion penetration decreased more with macrosynthetic fibers than with jute fibers, but the difference was minor.

(v) From the abrasion, as the microsilica substitution ratio increased, the abrasion resistance properties increased. With respect to the fiber type, the macrosynthetic fibers showed slightly better results than jute fibers.

(vi) For mixes that satisfied both the target strength goals and the target chloride ion penetration amount, with improved abrasion resistance, the results showed that when the microsilica substitution ratio was $3 \%$ or less and macrosynthetic fiber was used as the reinforcement fiber, LMFRCRSC performance improved for a concrete pavement emergency repair and satisfied the target values. Also, the microsilica would likely be used because of the high cost of microsilica and the marginal increase in benefits with increasing amounts.

\section{Conflicts of Interest}

The authors declare that they have no conflicts of interest.

\section{Acknowledgments}

This work was supported by the research grant of the Kongju National University in 2017.

\section{References}

[1] J. P. Won, J. M. Kim, S. J. Lee, S. W. Lee, and S. K. Park, “Mix proportion of high-strength, roller-compacted, latexmodified rapid-set concrete for rapid road repair," Construction and Building Materials, vol. 25, no. 4, pp. 1796-1800, 2011.

[2] ACI, "State-of-the-art report on roller compacted concrete pavements," 2 Tech. Rep.32510R-95, American Concrete Institute, Farmington Hills, MI, USA, 1995.

[3] J. La Hucik, S. Dahal, J. Roesler, and A. N. Amirkhanian, "Mechanical properties of roller-compacted concrete with macro-fibers," Construction and Building Materials, vol. 135, pp. 440-446, 2017.

[4] S. Krishna Rao, P. Sravana, and T. Chandrasekhar Rao, "Abrasion resistance and mechanical properties of roller compacted concrete with GGBS," Construction and Building Materials, vol. 114, pp. 925-933, 2016.

[5] S. Krishna Rao, P. Sravana, and T. Chandrasekhar Rao, "Investigating the effect of $\mathrm{M}$-sand on abrasion resistance of fly ash roller compacted concrete (FRCC)," Construction and Building Materials, vol. 118, pp. 352-363, 2016.

[6] J. N. Karadelis and Y. Lin, "Flexural strengths and fibre efficiency of steel-fibre-reinforced, roller-compacted, polymer modified concrete," Construction and Building Materials, vol. 93, pp. 498-505, 2015.

[7] J.-W. Han, J.-H. Jeon, and C.-G. Park, "Mechanical and permeability characteristics of latex-modified pre-packed 
pavement repair concrete as a function of the rapid-set binder content," Materials, vol. 8, no. 10, pp. 6728-6737, 2015.

[8] J. P. Won, J. H. Kim, C. G. Park, and J. W. Kang, "Shrinkage cracking of styrene butadiene polymeric emulsion-modified concrete using rapid-hardening cement," Journal of Applied Polymer Science, vol. 112, no. 4, pp. 2229-2234, 2009.

[9] M. Sprinkel, "Latex-modified concrete overlay containing type K cement," Tech. Rep. FHWA/VTRC 05-R26, Virginia Transportation Research Council, Charlottesville, VA, USA, 2005.

[10] M. Sprinkel, "High early strength latex modified concrete overlay," Tech. Rep. VTRC 88-R12, Virginia Transportation Research Council, Charlottesville, VA, USA, 1998.

[11] M. Sprinkel, "Very-early-strength latex-modified concrete over-lays," Tech. Rep. TAT99-TAR3, Virginia Transportation Research Council, Charlottesville, VA, USA, 1998.

[12] Z. J. Ricardo, "Development of rapid, cement-based repair materials for transportation structures," M.S. thesis, The University of Texas at Austin, Austin, TX, USA, 2013.

[13] D. H. Kim and C. G. Park, "Permeability, abrasion, and impact resistance of latex-modified fibre reinforced concrete for precast concrete pavement application," Progress in Rubber, Plastics \& Recycling Technology, vol. 29, pp. 239-254, 2013.

[14] R. O. Oh, D. H. Kim, and C. G. Park, "Durability performance of latex modified nylon fiber reinforced concrete for precast concrete pavement applications," Indian Journal of Engineering and Materials Sciences, vol. 21, pp. 49-56, 2014.

[15] D. H. Kim and C. G. Park, "Strength, permeability and durability of hybrid fiber-reinforced concrete containing styrene butadiene latex," Journal of Applied Polymer Science, vol. 129, pp. 1499-1505, 2013.

[16] S. K. Lee, M. J. Jeon, S. S. Cha, and C. G. Park, "Mechanical and permeability characteristics of latex-modified fiberreinforced roller-compacted rapid-hardening-cement concrete for pavement repair," Applied Sciences, vol. 7, no. 7, p. 694, 2017.

[17] A. Dousti, M. Shekarchi, R. Alizadeh, and A. Taheri-Motlagh, "Binding of externally supplied chlorides in micro silica concrete under field exposure conditions," Cement and Concrete Composites, vol. 33, no. 10, pp. 1071-1079, 2011.

[18] AASHTO, Standard Specification of Rigid Pavement, American Association of State Highway and Transportation Officials, Washington, DC, USA, 1998.

[19] Korea Expressway Corporation, Construction Material Quality and Standard for Highway Construction, Korea Expressway Corporation, Seongnam, Republic of Korea, 2005.

[20] ASTM C39, Standard Test Method for Compressive Strength of Cylindrical Concrete Specimens, American Society for Testing Materials, Philadelphia, PA, USA, 2015.

[21] ASTM C496/C496M, Standard Test Method for Splitting Tensile Strength of Cylindrical Concrete Specimens, American Society for Testing Materials, Philadelphia, PA, USA, 2011.

[22] ASTM C 78/C78M, Standard Test Method for Flexural Strength of Concrete (Using Simple Beam with Third-Point Loading), American Society for Testing Materials, Philadelphia, PA, USA, 2015.

[23] ASTM C1202, Standard Test Method for Electrical Indication of Concrete's Ability to Resist Chloride Ion Penetration, American Society for Testing Materials, Philadelphia, PA, USA, 2012.

[24] ASTM C944, Standard Test Method for Abrasion Resistance of Concrete or Mortar Surfaces by the Rotating-Cutter Method, American Society for Testing Materials, Philadelphia, PA, USA, 2012.
[25] J. P. Won, D. H. Lim, C. G. Park, and H. G. Park, "Bond behavior and flexural performance of structural synthetic fiber reinforced concrete," Magazine of Concrete Research, vol. 28, no. 6, pp. 401-410, 2003.

[26] J. P. Won, C. G. Park, S. W. Lee, C. I. Jang, and H. Y. Kim, "Performance of synthetic macrofibers in reinforced concrete for tunnel linings," Magazine of Concrete Research, vol. 61, no. 3, pp. 165-172, 2009.

[27] A. Bentur and S. Mindess, Fiber Reinforced Cementitious Composites, Elsevier Applied Science, London, UK, 1992. 


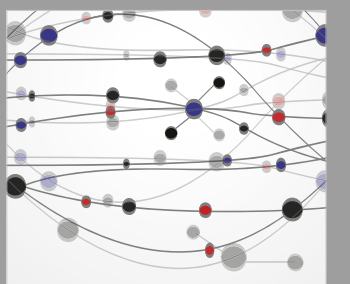

The Scientific World Journal
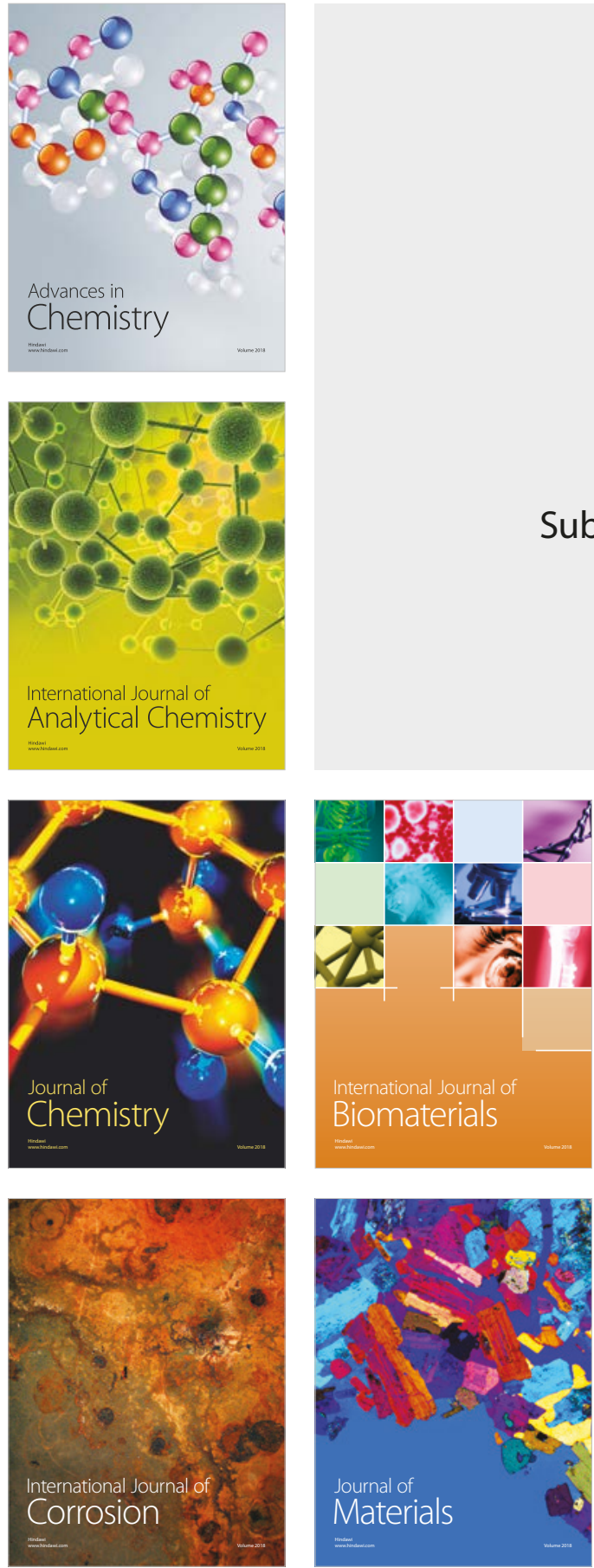

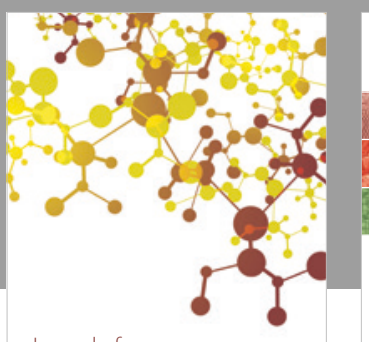

Journal of

Applied Chemistry
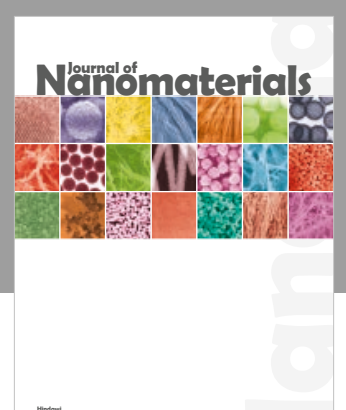

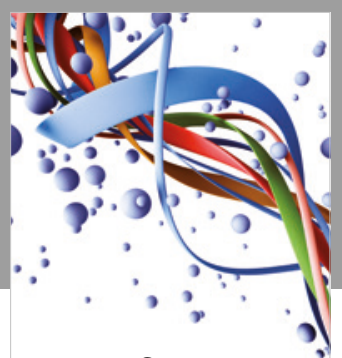

Scientifica

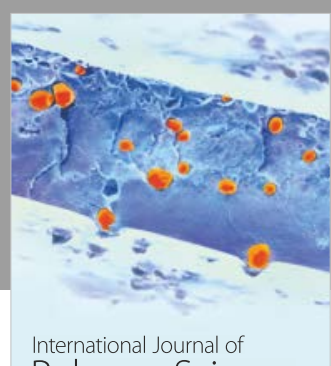

Polymer Science

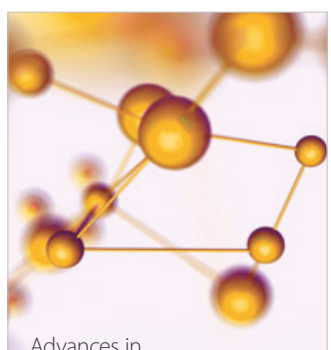

Physical Chemistry
